\title{
METÁFORAS VISUALES Y MULTIMODALES EN LAS VIÑETAS DE PRENSA: EN TORNO A LA IMAGEN DE LA CRISIS DEL 1-0
}

\author{
Magdalena Sędek \\ Universidad de Silesia en Katowice \\ http://dx.doi.org/10.18778/8220-201-4.27
}

\begin{abstract}
Resumen
El presente artículo versa sobre la representación metafórica que los principales diarios españoles dieron al referéndum por la independencia de Cataluña, celebrado el 1 de octubre de 2017, a través del texto multimodal de sus viñetas de opinión. Tras tipificarlas según los temas más comunes a los que van asociadas, se presta especial atención a una muestra de diez viñetas periodísticas cuyo sentido resulta de la interacción entre elementos lingüísticos e icónicos. Las imágenes metafóricas que emergen de ellas proporcionan una visión crítica del proceso soberanista catalán, así como corroboran la rotundidad con la que los humoristas gráficos expresaron sus juicios al respecto.
\end{abstract}

Palabras clave: Viñeta de prensa, metáfora, multimodalidad, Cataluña, independentismo.

\section{1.}

\section{A modo de introducción}

El presente artículo tiene por objetivo analizar la imagen de España en la época de la crisis surgida como consecuencia del referéndum por la independencia de Cataluña, celebrado el 1 de 
octubre de 2017. Examinando el tratamiento informativo que las principales cabeceras de la prensa diaria española realizaron por medio de sus viñetas de opinión, se propone indagar el papel que desempeñan los mecanismos metafóricos en la comprensión de la imagen mediática del famoso 1-O. De ahí que el corpus de estudio lo constituyan las viñetas publicadas en El País, El Mundo, La Vanguardia, ABC y La Razón entre los días 1 de septiembre y 31 de octubre de 2017, cuyo contenido viene determinado, en mayor o menor medida, por la cuestión separatista catalana ${ }^{1}$. La elección de ese periodo de tiempo extenso no es casual, puesto que se corresponde con los acontecimientos más significativos, que van desde principios de septiembre, cuando el Parlamento de Cataluña aprobó la Ley del Referéndum de Autodeterminación, mediante la celebración del mismo (el 1-O), hasta finales del mes de octubre, cuando se aplicó el artículo 155 de la Constitución y, poco después, el Tribunal Constitucional suspendió la Declaración Unilateral de Independencia. Además, cabe señalar que tal corpus nos permite estudiar la complejidad de los discursos relativos al referéndum catalán y a sus consecuencias políticas posteriores.

1 Según los datos de la Oficina de Justificación de la Difusión para el periodo enero-diciembre 2017, se trata de los cinco diarios de información general más difundidos en España. En el caso de El País contamos con las viñetas de Antonio Fraguas de Pablo (Forges) y Andrés Rábago García (El Roto); en el de El Mundo nos referimos a las viñetas de opinión de José María Gallego y Julio Rey (Gallego\&Rey), así como a las de Ángel y Francisco Javier Rodríguez Idígoras (Idígoras y Pachi). El humor gráfico en La Vanguardia es creado por Jaume Capdevila (Kap), en $A B C$ por José Manuel Puebla Ros (Puebla) y José María Nieto (JM Nieto). La Razón publica las viñetas del dúo Felipe Hernández Cava y Federico del Barrio (Caín). 


\section{Viñeta de prensa como género periodístico multimodal}

La viñeta de prensa es un tipo de género periodístico de opinión que, mediante la combinación de un código visual (diversos recursos de composición gráfica: encuadre, perspectiva, angulación, color, estilo del trazo, subcódigo gestual y cinético) y un código lingüístico (globos que incluyen comentarios y/o diálogos, carteles, rótulos, pancartas, letreros o títulos), representa, contextualiza e interpreta un determinado mensaje de la vida política, social o cultural, en tono jocoso ${ }^{2}$. Como lo subrayan Pedrazzini y Scheuer (2019: 124),

las viñetas humorísticas que articulan el dibujo y la escritura constituyen discursos multimodales en los que interactúan multiplicidad de signos icónicos, plásticos [...] y lingüísticos al servicio de una intencionalidad comunicativa y expresiva, con la finalidad última de denunciar, criticar, suscitar la reflexión, descargar tensiones y/o divertir. Tanto la producción como la interpretación de este tipo de discursos es simultánea [...], es decir que los modos semióticos son convocados al mismo tiempo y uno no funciona independientemente del otro.

A mbos modos aportan a la producción de sentido, aunque no en el mismo grado. De hecho, "[...] hay humoristas gráficos que otorgan al dibujo el papel principal (hasta el punto de que las palabras casi desaparecen) y humoristas que, en cambio, lo utilizan para completar o arropar la información que proporcionan las palabras" (Padilla García, Gironzetti, 2012: 94).

2 En opinión de Blanco Castilla (2007: 36), "el principal valor de la viñeta radica en que permite que los ciudadanos se enfrenten a su contenido, aun cuando éste sea de extrema dureza, desde una perspectiva más relajada, aunque no por ello más simplista o menos real". 
Conviene asimismo resaltar que, en la mayoría de los casos, la viñeta de prensa hace referencia a un acontecimiento muy actual, por lo cual "[...] el conocimiento del momento socio-histórico en el que surge es fundamental para su interpretación" (Michel, Ventura-Piselli, 2015: 343). Por consiguiente, además del componente textual y visual, las viñetas se caracterizan por la presencia de un tercer elemento imprescindible e implícito: el componente sociocultural. Así, en suma, el humor gráfico en forma de viñetas es "[...] un discurso [...] mixto óptico-verbal, breve, atractivo e ingenioso que explota las referencias culturales y contextuales compartidas entre el autor y los lectores para aportar un comentario crítico de la realidad sociopolítica" (Theofylakti, 2016: 42).

\section{3. \\ Metáfora visual y verbovisual en las viñetas periodísticas}

Sin duda alguna, la metáfora es un procedimiento recurrente en viñetas, de modo que estas últimas se convierten en un área comunicativa metafórica por excelencia ( $c f r$. Schilperoord, Maes 2009; Negro Alousque 2014; Forceville 2016). Efectivamente, como postula Peñamarín (1996: 109), la finalidad de la viñeta “[...] es el golpe, la colisión o superposición de dos perspectivas, lo que consigue por los procedimientos del humor o por los de la metáfora".

En líneas generales, se puede afirmar que las viñetas de prensa abundan en metáforas monomodales visuales (pictóricas) y multimodales verbovisuales. En las viñetas que solo contienen una pequeña apoyatura verbal "[...] el mensaje [...] suele coincidir con una metáfora visual que, por sí misma, evoca múltiples significados" (Agüero Guerra, 2013: 9). Dicho de otra manera, tal y como lo explica El Refaie (2009: 177), “[...] the visual mode differs from language in that it is simply not possible to represent abstract meaning visually without recourse to symbols, metonyms, or 
metaphors". En las viñetas de carácter inherentemente multimodal, en cambio, el lector tiene que descodificar y comprender un mensaje metafórico que resulta de la interacción entre imagen y palabra, combinados en una relación de complementariedad. Así pues, la construcción de metáforas multimodales es un proceso de fusión sígnica, dado que son metáforas "[...] in which target, source, and/or mappable features are represented or suggested by at least two different sign systems (one of which may be language) or modes of perception" (Forceville, 2008: 463).

\section{4. \\ Metáforas en la imagen de la crisis del 1-0}

Partiendo de un amplio corpus de 175 viñetas que transmiten opiniones sobre la cuestión separatista catalana en particular y sobre el nacionalismo en general, resulta posible determinar los principales ejes temáticos en los que se basaron los humoristas gráficos para construir sus mensajes. Entre los temas dominantes y recurrentes están los siguientes:

- la crítica al independentismo y al nacionalismo como corrientes político-sociales (60 viñetas);

- la preocupación por la organización de la consulta del 1-O y por las consecuencias de su resultado (34);

- la Declaración Unilateral de Independencia y la aplicación del artículo 155 (15);

- la protagonización de Rajoy, de Puigdemont y de Junqueras (44), de la Guardia Civil y de los Mossos d'Esquadra (12);

- la crisis catalana entendida como repetición de la historia (2);

- otros (8).

Cabe todavía aclarar que, debido al espacio asignado al presente estudio, en lo que sigue se comenta solamente una muestra más representativa de la totalidad de viñetas recogidas. 


\section{1. \\ Crítica al independentismo y al nacionalismo como corrientes sociopolíticas}

La descalificación al movimiento independentista y, en concreto, al separatismo catalán, ha sido uno de los temas más tratados por los viñetistas en los diarios españoles ${ }^{3}$. Algunos de ellos parten de la convicción de que el nacionalismo es inoperante como solución de los problemas y siempre actúa de manera interesada.

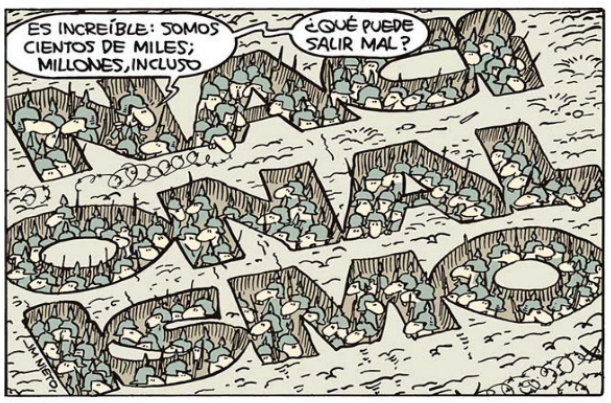

Figura 1. (JM Nieto, $A B C, 5.10 .2017$ )

Como podemos observar (fig. 1), JM Nieto refleja en su viñeta a un grupo bastante numeroso de personas refugiadas en las trincheras, vestidas de soldados y con un arma en las manos. No sin importancia es el hecho de que las zanjas defensivas toman la forma de la palabra 'nacionalismo'. Por ende, mediante la metáfora verbovisual LOS INDEPENDENTISTAS Y/O NACIONALISTAS SON LOS SOLDADOS ARMADOS EN LAS TRINCHERAS, la imagen reprueba “[...] a los nacionalistas, quienes, sin mediar motivo para desear tal independencia ni para fortificarse [...] adoptan una situación de inmovilismo y antidiálogo, así como de militarismo y populismo" (Requejo, Velasco, Reguero, 2016: 23). La viñeta en cuestión critica a los

3 Como afirma El Refaie (2009: 176), “a generic convention of cartooning [...] is that the goal is generally to expose something bad or shameful rather than to highlight the positive. Not surprisingly, cartoonist will thus often fall back on stereotypes and systematic metaphorical concepts that represent the complexity of the world in simpler and often very negative terms". 
independentistas catalanes por la estrechez de criterio y por la falta de una perspectiva más amplia que, tal vez, permitiría revelar el sinsentido del propósito secesionista. En los demás ejemplos recogidos, la aspiración a la independencia se la metaforiza como UN CAMINO SIN SENTIDO, UN ABISMO, UNA QUIMERA O UN SUEÑO DELIRANTE.

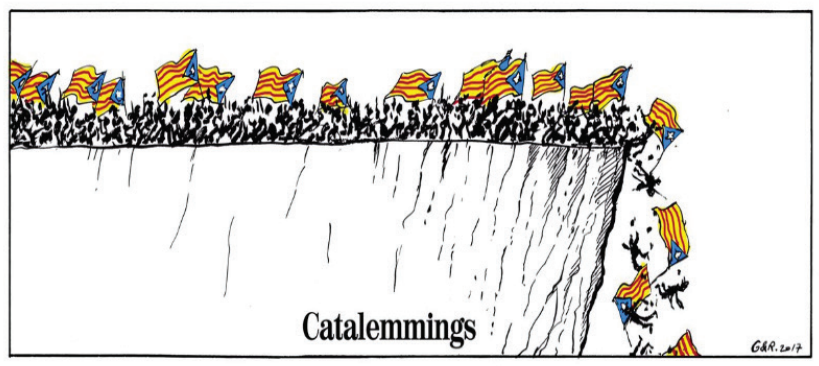

Figura 2. (Gallego\&Rey, El Mundo, 21.09.2017)

El siguiente subgrupo de viñetas centra el foco de sus críticas en los líderes del movimiento de independencia, así como en sus discursos reivindicativos y propagandísticos, comparados CON UNA ENFERMEDAD, UN CHAPAPOTE, UN NIVEL TÓXICO DE PARTÍCULAS (DE CINISMO) EN SUSPENSIÓN O UN REALITY SHOW. A los líderes mismos se los valora negativamente, ante todo, como sembradores de confusión, reprochándoles tendencias populistas y demasiado sentimentalismo. Los nacionalistas son vistos como FANTASMAS QUE VIVEN FUERA DE LA REALIDAD, atrapados en el pasado y obsesionados por la idea secesionista. Los manifestantes por la independencia, a su vez, impulsados e instigados por los políticos demagogos, se vuelven sus adeptos crédulos. En este sentido, la viñeta de Gallego\&Rey (fig. 2) hace un guiño al nacionalismo catalán criticando a sus partidarios. De acuerdo con la lectura metafórica de la imagen, LOS INDEPENDENTISTAS SON Los Lemmings (mejor dicho, CATALEMmings). Como es bien sabido, existe el mito de que los roedores en cuestión se suicidan en masa arrojándose al mar y, de esta forma, se autorregula su población. Esta leyenda urbana convirtió a la especie mencionada en sinónimo del comportamiento estúpido con resultados nefastos. Asimismo, los viñetistas retratan a los seguidores del 
independentismo como pasivos e instintivos, que solamente se suman a esa tendencia populista por estar de moda y no necesariamente por verdaderas convicciones.

\section{2. \\ Preocupación por la consulta del 1-0 y por sus consecuencias}

La pregunta planteada con motivo de la celebración del referéndum del 1-O (“ ¿Quiere que Cataluña sea un estado independiente en forma de república?"), a la que los votantes debían responder con un "sí" o "no", también encuentra su reflejo en el humor gráfico de aquellos días. Varias veces la alternativa ante la cual se sitúan los catalanes es comparada a la situación de indecisión expresada en la famosa línea del soliloquio de Hamlet: "Ser o no ser". Con el mismo leitmotiv está concebida la viñeta de Gallego\&Rey (fig. 3), publicada después de la aprobación de la Ley del Referéndum por el Parlamento de Cataluña. La viñeta en cuestión aprovecha el cartel oficial que promocionaba el referéndum del 1-0, utilizando la metáfora visual de una encrucijada de dos vías de tren. Cada una de ellas simboliza un camino que se puede escoger. Siguiendo este razonamiento es conveniente argumentar que participar en el referéndum es elegir un camino a seguir. Así, la viñeta apela al derecho a decidir subrayando: "Naciste con la capacidad de decidir". Los dibujantes de El Mundo añaden a esta imagen a la persona de Puigdemont en una dresina, quien en la segunda parte de la viñeta parece comprender que ningún camino sea el adecuado y, por lo tanto, huye por la tercera vía, como si presintiera complicaciones y quisiera esquivar la responsabilidad.
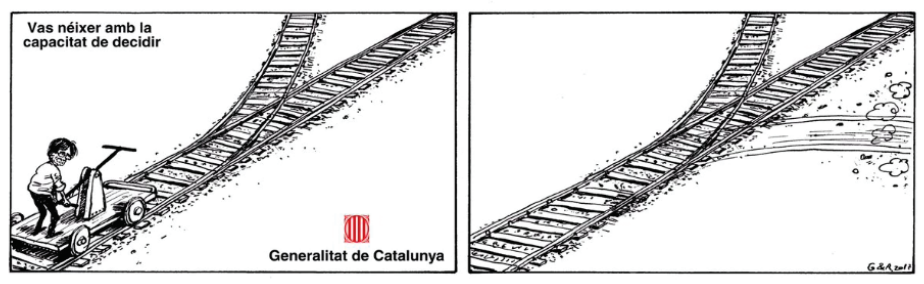

Figura 3. (Gallego\&Rey, El Mundo, 8.09.2017) 
De hecho, en todos los diarios analizados los humoristas gráficos representan la consulta soberanista como algo aciago y arriesgado. Con el propósito de plasmar esta idea, con frecuencia, identifican la cuestión independentista catalana con alguna amenaza o catástrofe que se cierne sobre el país y sus gobernantes. Entre las varias metáforas que encontramos en el corpus de estudio cabe realzar las que relacionan el referéndum con UN FUEGO DEVASTADOR, UN AGITADO REMOLINO DE AGUA O UNA TEMPESTAD. Pongamos como ejemplo la viñeta de Kap (fig. 4), donde se ilustra a Rajoy quien por metonimia representa al Gobierno español y sobre el que se desencadena la tormenta, es decir, la convocatoria del referéndum. Al otro lado del Atlántico aparece Trump, a quien le amenaza un poderoso y catástrofico ciclón tropical, Irma. Observando esta imagen se puede llegar a la conclusión de que la cuestión catalana constituye un fenómeno tan peligroso y capaz de provocar tantos daños como el huracán Irma que impactó en Estados Unidos a finales de agosto de 2017.

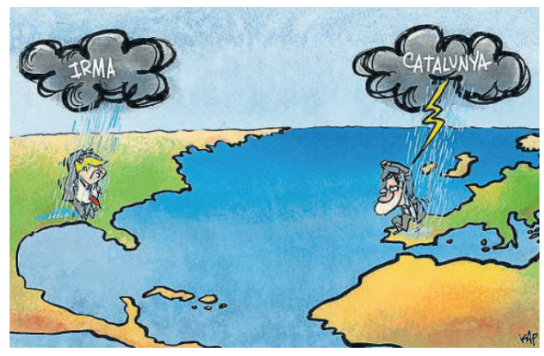

Figura 4. (Kap, La Vanguardia, 10.09.2017)

Además, es incuestionable que el tema del referéndum y la situación después de la votación suscitaron grandes emociones en la sociedad. Prueba de ello es la viñeta de Caín (fig. 5), cuyo contenido estriba en una amalgama entre un rótulo de advertencia, que informa comúnmente de un posible peligro causado por el alto voltaje, y la estelada azul, que metonímicamente alude a Cataluña y a la ideología independentista. Por consiguiente, la imagen permite crear una fórmula metafórica conforme a la cual LA CUESTIÓN SEPARATISTA CATALANA ES TAN PELIGROSA COMO EL ALto Voltaje. 


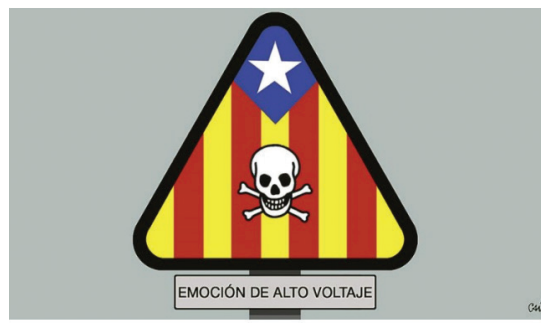

Figura 5. (Caín, La Razón, 16.10.2017)

Los viñetistas Gallego\&Rey (fig. 6), en cambio, van un paso más adelante en su interpretación de los hechos: el referéndum, sus resultados anunciados y las decisiones políticas posteriores son causa de la agonía de Cataluña y de sus dirigentes. En la ilustración, en una botella de cava, aparece Puigdemont que cava la tumba para "Catalunya" (que figura en la lápida sepulcral) y, tal vez, para sí mismo. De ello se infiere que la región de Cataluña, enclaustrada en la idea del separatismo (la botella), no tendrá cómo salir de la difícil situación en la que se ha sumido al convocar el referéndum. Así pues, ORGANIZAR LA CONSULTA INDEPENDENTISTA ES PREPARAR SU PROPIA TUMBA.

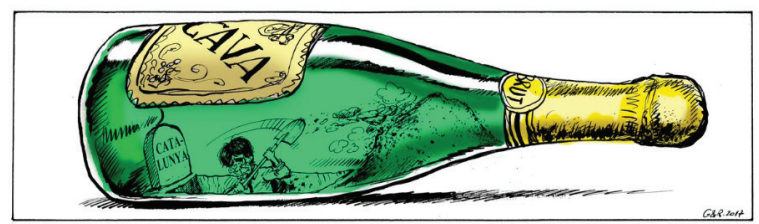

Figura 6. (Gallego\&Rey, El Mundo, 10.10.2017)

La preocupación por las consecuencias de la votación catalana se expresa en la mayoría de las viñetas analizadas mediante la idea de alejamiento. En efecto, los humoristas gráficos enfatizan en la autonomía de Cataluña y en la desmesura en sus exigencias separatistas al representar metafóricamente esta comunidad como si fuera EL ÚLTIMO PLANETA DEL SISTEMA SOLAR O UN NÁUfRAGO EN PLENo MAR. Otras viñetas se sirven del motivo de los puzles como elementos que forman la Península Ibérica y donde uno de ellos, que corresponde a Cataluña, no encaja en una figura deseada. La tendencia separatista de la comunidad 
mencionada y, por consiguiente, la división interna de España constituye, a la vez, un problema y un reto para los gobernantes. Tal como vemos en la viñeta de Idígoras y Pachi (fig. 7), el presidente del Gobierno se afana por arreglar un rompecabezas compuesto de dos piezas (Cataluña y el resto de España), por lo cual estamos ante la metáfora: TRATAR DE CONJURAR UNA CRISIS INDEPENDENTISTA ES INTENTAR RESOLVER UN ROMPECABEZAS. Ante el fracaso, Rajoy acaba pidiendo por algo más fácil de combinar, es decir, cinco mil piezas con montañas nevadas. La crítica al referéndum, como desmembrador, es clara, pero también son destacables la preocupación y la impotencia de los gobernantes ante sus consecuencias.

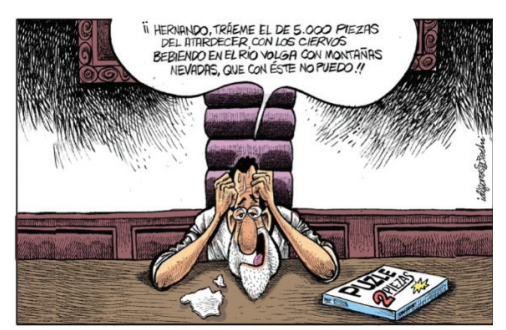

Figura 7. (Idígoras y Pachi, El Mundo, 14.10.2017)

\section{3. \\ Artículo 155 y la Declaración Unilateral de Independencia}

Un grupo considerable de viñetas del periodo analizado tiene incorporados dos símbolos, la sigla DUI y el número 155. Con el primero los dibujantes se refieren a la Declaración Unilateral de Independencia firmada el 10 de octubre por la mayoría del Parlamento catalán, aunque suspendida hasta el 27 de octubre, el día cuando claramente se proclamó la independencia de Cataluña. El segundo símbolo señala el artículo 155 de la Constitución española aplicado a Cataluña por el Gobierno el 27 de octubre, tras varios días de trámites. Dicho artículo permitió destituir por completo al gobierno de la Generalidad, disolver el Parlamento de Cataluña y convocar elecciones autonómicas catalanas para el día 21 de 
diciembre de 2017. El humor gráfico con frecuencia personifica al artículo 155, por lo cual este se convierte en UN VIAJANTE O UN DEPORTISTA en sus ejercicios de calentamiento. Además, los dibujantes resaltan su importancia, fuerza y alcance: lo consideran UN MONSTRUO, UN ELEFANTE, UN AMENAZADOR. Sirva de ejemplo la viñeta del dúo Idígoras y Pachi (fig. 8), en la que el artículo 155 visita a Puigdemont en su casa. Las palabras de saludo pronunciadas por un huésped inesperado ("He trasladado mi sede a Cataluña") son igualmente una alusión evidente a la famosa fuga de empresas 4 .

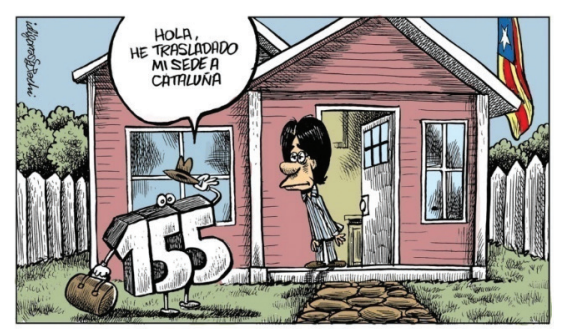

Figura 8. (Idígoras y Pachi, El Mundo, 21.10.2017)

Por otro lado, la alusión a la aplicación del artículo 155 y, en consecuencia, a la suspensión de la DUI por el Tribunal Constitucional, se realiza de forma implícita. Así, por ejemplo, la viñeta de El Roto (fig. 9) refleja una conversación mantenida entre la madre (España) y su hijo rebelde (Cataluña). La respuesta "Vale" que se da a la pregunta “¿Volvemos a casa?" conlleva la interpretación metafórica conforme a la que la aplicación del 155 pone fin al proceso separatista. Por tanto, la reintegración de Cataluña a España es el regreso de un hijo (pródigo) a casa.

4 Es conveniente aclarar que desde la celebración del referéndum del 1-O, las compañías empezaron a trasladar sus sedes sociales fuera de la región de Cataluña en búsqueda de mayor seguridad política y fiscal. El humor gráfico de aquellos días, sirviéndose de la exageración y de la ironía, también refleja ese aspecto. 


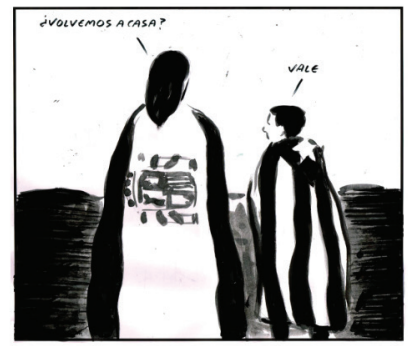

Figura 9. (El Roto, El País, 31.10.2017)

\section{4. \\ Protagonización de Rajoy y de Puigdemont}

El protagonismo humano del humor gráfico en el periodo estudiado pertenece, sin lugar a dudas, al entonces Presidente del Gobierno de España, Mariano Rajoy, y al Presidente de la Generalidad de Cataluña, Carles Puigdemont. La falta de comprensión y la lucha constante entre estos políticos, la aparente intención de dialogar a fin de salir del punto muerto o las acusaciones mutuas por la crisis catalana son cuestiones tratadas por los dibujantes en los distintos periódicos. Así, mediante las metáforas puramente visuales o verbovisuales, se retrata a los políticos mencionados como si fueran ASESINOS MUTUOS, SHERIFFS EN SU DUELO A PISTOLAS, PARTICIPANTES EN EL JUEGO DE LA SOGA O MAQUINISTAS DE TREN ${ }^{5}$. También es destacable su representación metafórica COMO NIÑOS QUE SE HACEN LOS INOCENTES en el contexto de la desintegración de España (fig. 10).

5 Cabe mencionar que la metáfora del choque de trenes, es decir, la imagen de dos locomotoras que avanzan la una hacia la otra, sin reparar en las normas que hayan podido saltarse ni pensar en la inminente catástrofe, es muy frecuente a la hora de aludir a un previsble choque de legitimidades entre el Estado y la Generalitat. 


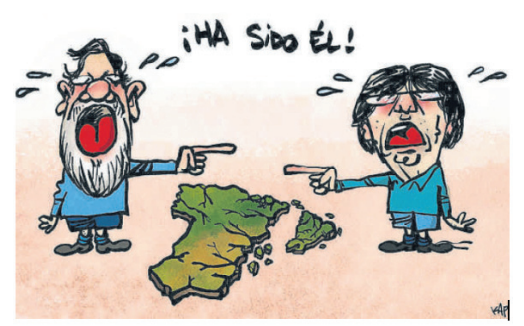

Figura 10. (Kap, La Vanguardia, 28.10.2017)

Otra ola de críticas por parte de los viñetistas cae sobre el propio Puigdemont, a quien se lo dibuja destacando su falta de respeto a la Constitución, así como atacando su aspiración por la independencia catalana sin tener en cuenta los principios de convivencia democrática. Los humoristas gráficos cuestionan también la veracidad de este político y la incongruencia en su comportamiento. De ahí que metaforicen a Puigdemont como:

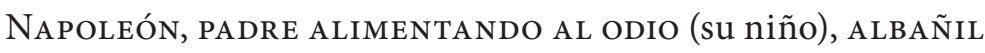
ELEVANDO UN MURO (antidiálogo), ACTOR ENSAYANDO SU PAPEL (de víctima), EQUILIBRISTA O ARTISTA DE CIRCO, entre muchos más.

\section{5. \\ A modo de conclusión}

Parece innegable que el estudio de los elementos textuales e icónicos en viñetas periodísticas, que configuran un texto multimodal, desemboca en la comprensión del mensaje global que el autor y su medio desean comunicar. Igual de importante resulta ser el conocimiento de los factores políticos, económicos y sociales en un momento histórico dado. En consecuencia, el análisis de la integración texto-imagen-componente sociocultural "[...] gives evidence of the presence of monomodal visual (and multimodal verbo-pictorical) metaphor and visual metonymy in political cartooning" (Negro Alousque, 2013: 380). 
El referéndum de autodeterminación, organizado el 1 de octubre por los entonces dirigentes de Cataluña, ha sumido a España en una de sus mayores crisis políticas de la actualidad. Esta cuestión ha recibido una fuerte cobertura a través del humor gráfico. Las viñetas periodísticas de opinión, publicadas en los diarios de ámbito nacional y pese a su pluralidad ideológica manifiesta, han repetido la misma argumentación y, por lo tanto, una iconografía parecida (metáforas, metonimias, símbolos) para referirse al referéndum catalán y a las consecuencias que este acarrearía. Al abordar el tema a través de varios ejes temáticos, los viñetistas se han mostrado críticos respecto al proceso independentista y han expuesto su oposición al nacionalismo, reprochándole su falta de bases ideológicas, el populismo de sus líderes, la insensatez de sus seguidores y el sensacionalismo que genera. Han tratado el referéndum soberanista en términos de amenaza, catástrofe y preocupaciones amontonadas. Es asimismo llamativo bastante protagonismo que se ha otorgado al líder del procés, Puigdemont, y de la posición centralista, Rajoy, en la representación gráfica de la cuestión separatista catalana.

\section{Referencias bibliográficas}

Agüero Guerra, M. (2013), "Análisis semántico-cognitivo del discurso humorístico en el texto multimodal de las viñetas de Forges", ELUA, 27, 7-30.

Blanco Castilla, E. (2007), "La viñeta como nueva estrategia editorial de los medios. Visualización del 11-M en los principales escenarios mediáticos", Ámbitos: Revista internacional de comunicación, 16, 27-36.

El Refaie, E. (2009), "Metaphor in political cartoons: Exploring audience responses", en Ch. Forceville y E. Urios-Aparisi (eds.), Multimodal Metaphor, Berlin/New York: Mouton de Gruyter, 173-196.

Forceville, Ch. (2008), "Metaphor in Pictures and Multimodal Representations", en R. W. Gibbs Jr. (ed.), The Cambridge Handbook of Metaphor and Thought, Cambridge: Cambridge University Press, 462-482. 
Michel, M., Ventura-Piselli, R. (2015), “Metáfora visual en la caricatura política: representaciones actuales de la inmigración en los EE.UU. e Italia”, Jornaler@s, 2, 343-351.

Negro Alousque, I. (2013), "Visual Metaphor and Metonymy in French Political Cartoons", RESLA, 26, 365-384.

Padilla García, X., Gironzetti, E. (2012), "Humor e ironía en las viñetas cómicas periodísticas en español e italiano: un estudio pragmático y sociocultural”, Foro hispánico: revista hispánica de Flandes y Holanda, 44, 93-133.

Pedrazzini, A., Scheuer, N. (2019), "Sobre la relación verbal-visual en el humor gráfico y sus recursos", Cuadernos del Centro de Estudios en Diseño y Comunicación, 74, 123-141.

Peñamarín, C. (1996), "El humor gráfico y la metáfora polémica", La Balsa de la Medusa, 38-39, 107-132.

Requejo M., Velasco, A. M., Reguero, I. (2016), “El humor gráfico español ante el reférendum escocés del 18 de septiembre de 2014 ¿Dibujando la independencia de Cataluña?”, Historia y Comunicación Social, 21 (1), 15-37.

Theofylakti, Z. (2016), "Humor y discurso político: El humor como recurso de opinión y crítica en la prensa contemporánea griega y española", [en línea] <https://repositori.upf.edu/handle/10230/26894>, [fecha de consulta: 20.11.2018]. 